CHRONIC OBSTRUCTIVE PULMONARY DISEASE

\title{
Effect of exacerbations on quality of life in patients with chronic obstructive pulmonary disease: a 2 year follow up study
}

\author{
M Miravitlles, M Ferrer, À Pont, R Zalacain, J L Alvarez-Sala, F Masa, H Verea, C Murio, F Ros, \\ R Vidal, for the IMPAC Study Group*
}

Thorax 2004;59:387-395. doi: 10.1136/thx.2003.008730

See end of article for authors' affiliations

Correspondence to:

Dr M Miravitlles, Servei de Pneumologia, Institut Clínic de Pneumologia i Cirurgia Toràcica, Hospital Clinic

Villarroel 170, 08036

Barcelona, Spain;

marcm@clinic.ub.es

Received 15 April 2003

Accepted

30 December 2003 exacerbations and their impact on the health related Background: A study was undertaken to evaluate exacerbations and their impact on the
quality of life (HRQL) of patients with chronic obstructive pulmonary disease (COPD). Methods: A 2 year follow up study was performed in 336 patients with COPD of mean (SD) age 66 (8.2) years and mean (SD) forced expiratory volume in 1 second $\left(\mathrm{FEV}_{1}\right) 33(8) \%$ predicted. Spirometric tests, questions regarding exacerbations of COPD, and HRQL measurements (St George's Respiratory Questionnaire (SGRQ) and SF-12 Health Survey) were conducted at 6 month intervals.

Results: A total of 1015 exacerbations were recorded, and 103 (30.7\%) patients required at least one hospital admission during the study. After adjustment for baseline characteristics and season of assessment, frequent exacerbations had a negative effect on HRQL in patients with moderate COPD (FEV 1 $35-50 \%$ predicted); the change in SGRQ total score of moderate patients with $\geqslant 3$ exacerbations was almost two points per year greater (worse) than those with $<3$ exacerbations during the follow up $(p=0.042)$. For patients with severe COPD (FEV $1<35 \%$ predicted) exacerbations had no effect on HRQL. The change in SGRQ total score of patients admitted to hospital was almost 2 points per year greater (worse) than patients not admitted, but this effect failed to show statistical significance in any severity group. There was a significant and independent seasonal effect on HRQL since SGRQ total scores were, on average, 3 points better in measurements performed in spring/summer than in those measured in the winter $(p<0.001)$.

Conclusions: Frequent exacerbations significantly impair HRQL of patients with moderate COPD. A significant and independent effect of seasonality was also observed.
C hronic obstructive pulmonary disease (COPD) is a highly prevalent disease, and it is estimated that 7$10 \%$ of the adult population may be affected. ${ }^{1} \mathrm{COPD}$ is a frequent cause of morbidity and disability, and even patients with mild COPD present with substantially compromised heath related quality of life (HRQL). ${ }^{2}$ Since one of the main objectives in the management of patients with COPD is to improve or preserve their health status, ${ }^{3}$ it is crucial to identify factors provoking persistent deterioration in HRQL.

The chronic and progressive course of COPD is often aggravated by short episodes of increasing respiratory symptoms. These exacerbations of COPD are frequent events in the natural history of the disease. Patients with moderate to severe disease experience a mean of two episodes per year. The number of episodes is dependent on the level of ventilatory impairment. ${ }^{4}$ Furthermore, an increased number of past exacerbations is one of the best predictors for the risk of future recurrent exacerbations ${ }^{5}$ and relapse after treatment. ${ }^{6}$

A recent study has shown that exacerbations produce a severe short term deterioration in HRQL that improves a few days after treatment. ${ }^{7}$ The long term impact of exacerbations has only been assessed in one previous study in 70 patients. Patients were followed for 1 year and the results showed that patients experiencing a higher number of exacerbations had significantly worse HRQL scores at the end of the study. ${ }^{8}$ However, HRQL measurements were not performed at

* Investigators participating in the IMPAC study are listed in the appendix. baseline, and it is possible that worse HRQL scores were already present at the beginning of the study in patients with frequent exacerbations. In addition, the magnitude of the impact of exacerbations on HRQL scores could not be investigated in the aforementioned study in the absence of a baseline HRQL measure. ${ }^{8}$

In the present study a large cohort of patients with moderate to severe COPD was followed prospectively over 2 years. The evolution of HRQL and the effects of exacerbations and hospital admissions on HRQL were assessed.

\section{METHODS}

\section{Study sample}

Full details of the patient selection criteria have been reported elsewhere. ${ }^{9}$ Four hundred and forty one patients (432 men) with a diagnosis of COPD according to guidelines ${ }^{10}$ were recruited consecutively from 39 secondary and tertiary referral centres throughout Spain. The main inclusion criteria were: current or ex-smokers, age $>40$ years, and an irreversible component of airflow obstruction in pulmonary function tests. Airflow obstruction was defined as an irreversible component if the forced expiratory volume in 1 second $\left(\mathrm{FEV}_{1}\right)$ was less than $70 \%$ of predicted and the ratio of $\mathrm{FEV}_{1}$ /forced vital capacity (FVC) was less than $70 \%$ before and after the use of bronchodilators. Post-bronchodilator

Abbreviations: $\mathrm{BMI}$, body mass index; COPD, chronic obstructive pulmonary disease; $F E V_{1}$, forced expiratory volume in 1 second; $F V C$, forced vital capacity; HRQL, health related quality of life; SGRQ, St

George's Respiratory Questionnaire 
$\mathrm{FEV}_{1}$ was used to classify patients as stage II ( $\mathrm{FEV}_{1}$ 35-50\% predicted) and stage III ( $\mathrm{FEV}_{1}<35 \%$ predicted) COPD based on the ATS classification. ${ }^{11}$ All patients were in a stable phase with neither an acute clinical decline nor a hospital admission for at least 1 month before enrolment in the study. Exclusion criteria included asthma, significant bronchiectasis, carcinoma of the bronchus or other active solid or haematological neoplasms, a life expectancy of less than 2 years due to non-COPD diseases, and inability to understand or complete the HRQL questionnaires.

The study was approved by all relevant institutional ethical committees, and written informed consent was obtained from all study participants.

\section{Patient evaluation}

Participants were recruited during a 2 month period (January and February 1999) and were scheduled to attend four follow up visits at 6 month intervals over 2 years. Patients in a nonstable phase were identified by the attending physician during a scheduled follow up visit. The visit was then rescheduled for at least 2 weeks later or for a future date pending clinical stability. At the time of study enrolment and follow up visits, $\mathrm{FEV}_{1}, \mathrm{FVC}$, and bronchodilator response were measured and the Spanish versions of the St George's Respiratory Questionnaire (SGRQ) ${ }^{12}{ }^{13}$ and the SF-12 Health Survey were completed by the patient. ${ }^{14}{ }^{15}$ Spirometric procedures were performed according to ATS criteria. ${ }^{16}$

The SGRQ is a supervised, self-administered measure specifically designed for evaluation of airway disease. Scores vary from 0 (no disability or perfect health status) to 100 (maximum disability or worst health status). A change of four units in the SGRQ score is considered clinically significant. ${ }^{17}$ The SGRQ is a valid measure of health status and well being in chronic airflow limitation and correlates with changes following treatment. ${ }^{12} 18$ It was completed under the supervision of clinical staff and according to guidelines in the manual.

The SF-12 Health Survey is a reduced version of the SF-36 Health Survey and contains 12 items. ${ }^{14}$ These 12 items may account for more than $90 \%$ of the variance of summary measures of the SF-36. Two scores are calculated based on the SF-12 survey-the physical summary (PCS-12) and the mental summary (MCS-12)-using a value of 50 with standard deviation of 10 units as the reference population. In this report the Spanish adult general population was used as the reference population. ${ }^{15}$ In contrast to the SGRQ scoring system, higher scores in the SF-12 survey indicate an improved health status, with values of $>50$ indicating an improved health status compared with the reference population. Questionnaires were monitored for missed items throughout the study and reports were sent to each centre regularly.

The presence of co-morbid conditions was determined by verifying with patients the existence of any of 13 chronic conditions. ${ }^{2}$ An index of co-morbidity was computed based on the number of chronic conditions reported. At each follow up visit detailed information on the number of exacerbations and hospital admissions due to COPD during the last interval were collected. Data were monitored on site twice during the study; once at the end of the enrolment period to verify the accuracy of data and compliance with inclusion and exclusion criteria and again before the last control visit to verify medical records for evidence of unreported exacerbations and hospital admissions.

\section{Exacerbations}

The consensus definition of exacerbation used was "a sustained worsening of the patient's condition, from stable state characterised by the increase of any combination of three cardinal symptoms: dyspnoea, sputum purulence, and sputum volume, that is acute in onset and necessitates a change in regular medication". ${ }^{19}$ Patients were instructed to attend unscheduled visits whenever they noticed a deterioration in symptoms. If their symptoms were compatible with an exacerbation, antibiotics and/or oral steroids and/or increased doses of inhaled steroids and bronchodilators were prescribed. The characteristics of these exacerbations, treatment administered, and their clinical evolution have been presented elsewhere. ${ }^{20}$ Detailed information on hospital admissions and exacerbations that were not attended by the investigators (due to treatment at home or at other centres) was retrospectively collected at the follow up visits. The total number of exacerbations was obtained by combining the number of exacerbations attended by the investigators and those reported by the patients at follow up visits. Patients were divided into two groups: those with $\geqslant 3$ exacerbations (frequent) and those with 0-2 exacerbations (infrequent), according to the median number of three exacerbations over 2 years.

\section{Statistical analysis}

Descriptive statistics were generated to examine the demographic and disease characteristics of the patients. Figures showing the evolution during follow up of quality of life scores and spirometric values according to the number of exacerbations were constructed. Differences between groups were tested using the unpaired $t$ test or $\chi^{2}$ test, depending on the nature of the variables. Analysis of data was performed using the Statistical Package for the Social Sciences (SPSS) version 10 .

To examine the difference between patients with frequent and infrequent exacerbations in total SGRQ score and its change during follow up (including the five evaluations), Generalised Estimating Equations (GEE) for repeated measures were applied using Stata Release 6.0 (StataCorp, Texas, USA). This method takes into account the correlation within subjects. $^{21}$ The interactions between the most important factors were tested. The interaction between exacerbations and COPD severity was statistically significant, showing that the effect of exacerbations on SGRQ total score was modified by severity group. Two models - one for each severity groupwere therefore constructed. To allow the interpretation of coefficients as SGRQ total score differences for a typical patient-that is, with the average characteristics of the sample-the baseline characteristics of patients used for adjustment were included as follows: (a) the continuous variables (age, BMI, smoking consumption, and years of evolution of COPD) were mean centred (removing sample means); and (b) the categorical variables (number of coexisting chronic conditions, COPD severity, and dyspnoea) were transformed by using the deviations from the means coding. For differences within patients, coefficients of interaction terms between each factor and repeated measures were calculated as total SGRQ score changes by year.

\section{RESULTS}

Of the 441 patients enrolled in the study, five had insufficient data at baseline assessment so a total of 436 patients were evaluated. Of these 436 patients, 45 (10.3\%) died and 55 $(12.6 \%)$ were lost to follow up, leaving 336 patients who completed the study and were valid for analysis. Causes of death included COPD $(n=13)$, cardiac disease $(n=7)$, lung cancer $(n=4)$, other cancers $(n=4)$, stroke $(n=4)$, complications of lung transplant $(n=2)$, pneumonia $(n=2)$, acute intestinal ischaemia $(n=1)$, pancreatitis $(n=1)$, hepatitis $(\mathrm{n}=1)$, and unknown $(\mathrm{n}=6)$. Table 1 shows the demographic and clinical characteristics of the patients who completed the study and those who were lost to follow up. 
No significant differences were found between baseline parameters in these two groups, with the exception of BMI which was lower in patients lost to follow up than in those who completed the study ( $26.1 \vee 27.4 ; 95 \%$ CI 0.24 to 2.42$)$. $328(97.6 \%)$ of the study participants were men, the mean (SD) age was 66 (8.2) years, and mean (SD) tobacco consumption was 55 (30.3) pack years. Participants exhibited a marked impairment at baseline: mean (SD) $\mathrm{FEV}_{1} 33.0$ (8.0)\% predicted, mean (SD) SGRQ total score 47.6 (17.2), and PCS-12 score 38.2 (9.2). No significant deterioration was observed in MCS-12 score (49.7 (12.4) units). Seventy percent of patients reported at least one co-existing chronic condition, hypertension being the most common (22.4\%).

\section{Exacerbations}

During the 2 year study 457 exacerbations were attended by the investigators. Information on an additional 558 exacerbations was collected during the four follow up visits and/or during on site monitoring of clinical records. These episodes were either attended by the primary care physician, by another specialist when patients were temporarily away from home, or by the hospital emergency departments. A total of 1015 exacerbations were reported by 287 patients, or a mean of 1.5 exacerbations per patient per year. The distribution of exacerbations was as follows: $49(14.6 \%)$ patients did not experience any exacerbation, $63(18.8 \%)$ experienced one episode, $66(19.6 \%)$ two episodes, 51 (15.2\%) three episodes, and 107 (31.8\%) four or more. A total of 103 patients (30.7\%) were admitted to hospital at least once due to an exacerbation during the 2 years. The number of exacerbations in the different periods of the study and their characteristics are shown in table 2 . The frequency of exacerbations varied over the four periods of the study, being higher in the second and fourth periods which included the autumn and first months of winter ( $n=362$ and $n=251$, respectively) than in the first and third periods comprising mostly the spring and summer ( $\mathrm{n}=201$ for both periods). On average, patients had 1.7 exacerbations during the first year and 1.3 during the second year $(p=0.001)$.

Complete information on the treatment administered was available for the 457 reported exacerbations. Oral steroids were prescribed in 189 (41.4\%). No differences were observed in the frequency of prescription of oral steroids in the different periods of the study $(\mathrm{p}=0.79$, table 2$)$.

The mean (SD) time period between the last reported exacerbation and the clinical visit with HRQL evaluation was
60.6 (51.0) days. There were no significant differences in the time period between the last exacerbation and clinical visit during the different evaluations $(p=0.14)$ and no differences were found between frequent and infrequent exacerbators ( $p>0.05$ in all periods, table 2$)$.

\section{Differences between patients with frequent and infrequent exacerbations at baseline and after 2 years}

Significant differences between patients with infrequent and frequent exacerbations were observed for baseline $\mathrm{FEV}_{1}$ (34.2\% predicted $v 31.8 \%$ predicted, $95 \%$ CI of difference 0.8 to 4.6$)$. In addition, all individual domains and SGRQ total score were significantly higher (that is, worse) at baseline in patients who experienced frequent exacerbations during follow up (95\% CI -11.7 to -3.2 for symptoms, -12.1 to -3.2 for activity, -10.7 to -3.2 for impact, and -10.9 to -3.7 for total score). The differences in mean values in all domains were higher than the four points considered clinically significant. Similarly, significant differences were observed in PCS-12 (95\% CI 0.85 to 4.73 ) but not in MCS-12 ( $95 \%$ CI -0.76 to 4.56 ). At the end of the 2 year follow up period most measurements showed an improvement in the scores, which was of higher magnitude in the symptoms subscale. Differences in HRQL scores between patients with frequent and infrequent exacerbations persisted and even increased at the end of the study compared with baseline (table 3).

\section{Influence of exacerbations on HRQL during 2 year follow up period}

HRQL scores of the COPD population improved during follow up. The highest improvement in SGRQ scores occurred during the first 6 months of the study-that is, between the enrolment visit and the second visit. All SGRQ scores were higher (that is, worse HRQL) in evaluations performed during the winter season (third and fifth visits) than in those conducted during the spring/summer seasons (second and fourth visits). These differences were greatest in the SGRQ symptoms subscale (fig 1). No significant differences were observed in SF-12 scores related to seasonality (data not shown).

The evolution of the SGRQ scores showed that the greatest differences between frequent and infrequent exacerbators were observed in the symptoms scale. Both groups experienced an improvement in the scores in this subscale, but patients

Table 1 Baseline characteristics of patients

\begin{tabular}{|c|c|c|}
\hline & Completed follow up ( $n=336$ ) & Lost to follow up ( $n=55$ ) \\
\hline Sex (male), n (\%) & $328(97.6 \%)$ & $54(98.2 \%)$ \\
\hline Mean (SD) age (years) & $66.1(8.2)$ & $67.1(9.3)$ \\
\hline Mean (SD) BMI $\left(\mathrm{kg} / \mathrm{m}^{2}\right)$ & $27.4(4)$ & $26.2(4.0)^{*}$ \\
\hline \multicolumn{3}{|l|}{ Severity of COPD, $n(\%)$} \\
\hline II (FÉ, $35-49 \%)$ & $147(43.8 \%)$ & $20(36.4 \%)$ \\
\hline III $\left(\mathrm{FEV}_{1}<35 \%\right)$ & $189(56.3 \%)$ & $35(63.6 \%)$ \\
\hline Mean (SD) pack years & $55.0(30.3)$ & $65.0(44.2)$ \\
\hline \multicolumn{3}{|l|}{ Mean (SD) spirometric values } \\
\hline $\mathrm{FVC}(\mathrm{ml})$ & $2222.5(640.2)$ & $2208.7(716.2)$ \\
\hline FVC (\% over predicted) & $53.6(13.4)$ & $52.6(14.6)$ \\
\hline $\mathrm{FEV}_{1}(\mathrm{ml})$ & $1016.7(287.4)$ & $980.9(290.1)$ \\
\hline FEV $1 \%$ over predicted) & $33.0(8.0)$ & $31.5(8.1)$ \\
\hline $\mathrm{FEV}_{1} / \mathrm{FVC}$ ( $\%$ over predicted) & $64.2(13.9)$ & $63.3(15.6)$ \\
\hline \multicolumn{3}{|l|}{ Mean (SD) quality of life scores } \\
\hline SGRQ Symptoms & $48.3(20.2)$ & $53.3(21.8)$ \\
\hline SGRQ Activity & $62.8(20.9)$ & $65.3(19.4)$ \\
\hline SGRQ Impacts & $38.7(17.8)$ & $41.8(18.4)$ \\
\hline SGRQ Total & $47.6(17.2)$ & $50.8(17.2)$ \\
\hline
\end{tabular}


Table 2 Exacerbations by patients with frequent and infrequent exacerbations in different periods of the study

\begin{tabular}{|c|c|c|c|c|c|}
\hline & \multicolumn{3}{|c|}{ Number of exacerbations } & \multicolumn{2}{|c|}{ Characteristics of reported exacerbations } \\
\hline & Not reported, $n(\%)$ & Reported, $\mathbf{n}(\%)$ & Total & $\begin{array}{l}\text { Treated with oral } \\
\text { steroids, } \mathbf{n}(\%)\end{array}$ & $\begin{array}{l}\text { Mean (SD) time between } \\
\text { last exacerbation and } \\
\text { evaluation (days) }\end{array}$ \\
\hline \multicolumn{6}{|c|}{ First period (1 st to 2 nd evaluation) } \\
\hline Infrequent exacerbator & $15(42.9 \%)$ & $20(57.1 \%)$ & 35 & $5(25 \%)$ & $51.6(36.8)$ \\
\hline Frequent exacerbator & $66(39.8 \%)$ & $100(60.2 \%)$ & 166 & $44(44 \%)$ & $52.8(40.2)$ \\
\hline p value ${ }^{*}$ & 0.734 & & & 0.115 & 0.901 \\
\hline \multicolumn{6}{|c|}{ Second period (2nd to 3 rd evaluation) } \\
\hline Infrequent exacerbator & $44(55 \%)$ & $36(45 \%)$ & 80 & $12(33.3 \%)$ & $52.1(65.7)$ \\
\hline Frequent exacerbator & $160(56.7 \%)$ & $122(43.3 \%)$ & 282 & $58(47.5 \%)$ & $65.7(59.0)$ \\
\hline p value ${ }^{*}$ & 0.782 & & & 0.132 & 0.281 \\
\hline \multicolumn{6}{|c|}{ Third period (3rd to 4th evaluation) } \\
\hline Infrequent exacerbator & $17(54.8 \%)$ & $14(45.2 \%)$ & 31 & $7(50 \%)$ & $79.6(55.6)$ \\
\hline Frequent exacerbator & $95(55.9 \%)$ & $75(44.1 \%)$ & 170 & $27(36 \%)$ & $53.9(42.2)$ \\
\hline p value ${ }^{*}$ & 0.914 & & & 0.322 & 0.061 \\
\hline \multicolumn{6}{|c|}{ Fourth period (4th to $5^{\text {th }}$ evaluation) } \\
\hline Infrequent exacerbator & $32(65.3 \%)$ & $17(34.7 \%)$ & 49 & $3(17.6 \%)$ & $60.4(40.3)$ \\
\hline Frequent exacerbator & 129 (63.9\%) & $73(36.1 \%)$ & 202 & $33(45.2 \%)$ & $74.7(58.6)$ \\
\hline p value* & 0.850 & & & 0.037 & 0.367 \\
\hline Total & 558 & 457 & 1015 & $189(41.4)$ & $60.6(51.0)$ \\
\hline $\mathrm{p}$ valuet & $<0.001$ & & & 0.798 & 0.140 \\
\hline
\end{tabular}

with infrequent exacerbations improved by -10.77 points while those with frequent exacerbations improved by -5.61 points $(95 \%$ CI -9.46 to -0.87 ; table 3 , fig 1$)$. The time course of the SGRQ scores during follow up for moderate and severe patients stratified according to the number of exacerbations is shown in fig 2. At baseline both groups of severe patients exhibited worse HRQL than moderate patients. However, at the end of the follow up period moderate patients with frequent exacerbations had worse HRQL scores than severe patients with infrequent exacerbations (fig 2). This observation highlights the impact of exacerbations, particularly in patients with moderate COPD.

No significant differences in $\mathrm{FEV}_{1}$ (\%) were observed during the 2 year follow up period. A trend to increased values at the second and fourth evaluation (spring and summer months) was observed, especially in moderate patients, although the magnitude of the change was not statistically significant and probably not clinically relevant. No differences were observed between the first and the last evaluation of lung function (fig 2). For example, mean (SD) $\mathrm{FEV}_{1}$ was $36.39(8.96) \%$ at baseline and $36.95(13.62) \%$ at completion of the study.

Results of the GEE models obtained to examine the independent influence of frequent exacerbations during follow up on the five repeated measures of SGRQ total score and its change over time are shown in table 4 for patients with moderate COPD and in table 5 for patients with severe disease. The differences between groups of patients according to factors evaluated are shown in the left part of the tables. After adjusting for baseline characteristics and season of evaluation, statistically worse quality of life was estimated for moderate patients with frequent exacerbations during follow up (5.45 points higher total SGRQ score than reference group, $\mathrm{p}=0.013)$, and for severe patients with any hospital admission during follow up ( 5.53 points higher total SGRQ score than reference group, $\mathrm{p}=0.007)$. The effect of season on HRQL was statistically significant in both severity groups, with lower (better) scores in the evaluations performed during the summer $(-3.00$ and -2.97 , respectively, $p<0.001)$. From baseline clinical characteristics of patients, only the degree of dyspnoea explained differences between patients in total SGRQ scores, whatever the severity group.

The differences within patients according to the factors evaluated are shown in the right part of tables 4 and 5, and coefficients should be interpreted as the difference in the SGRQ total score change by year experienced by any given typical patient who exhibits the characteristic compared with the reference category. The mean annual rate of change in the SGRQ score was $-2.58(95 \%$ CI -4.0 to -1.1$)$ for moderate patients and -1.75 (95\% CI -4.6 to 1.1$)$ for patients with severe disease. Patients who were admitted to hospital during the follow up period had a larger increase (that is, HRQL worse) in the total score than those not admitted, but this effect just failed to show statistical significance in either severity group ( 1.8 and 1.6 per year, $p=0.091$ and $p=0.066$, respectively). Similarly, suffering frequent exacerbations during the follow up period was significantly and independently associated with a significant impairment in the total SGRQ score only for moderate patients. The differences were considerable in this group, those with frequent exacerbations having a change of -0.6 points per year $(95 \%$ CI -2.58 to 1.98 applying regression coefficients in table 4) compared with a change of -2.58 points per year (that is, HRQL improved) in those with infrequent exacerbations. Because of the effect of exacerbations on HRQL, moderate patients with frequent exacerbations had a slightly worse SGRQ total score at the end of the study than severe patients with infrequent exacerbations (fig 2).

Among the baseline characteristics, the degree of dyspnoea was also significantly associated with a change in SGRQ total score over time.

\section{DISCUSSION}

In patients with COPD, exacerbations and hospital admissions were associated with long term effects on HRQL. After controlling for baseline characteristics, among patients with moderate COPD, those with frequent exacerbations had a greater change in SGRQ total score (2 units per year) than those with infrequent exacerbations. Similarly, hospital admissions resulted in an increased change of almost 2 units per year in SGRQ total scores in both moderate and severe COPD patients, but this effect just failed to show statistical significance. A significant and independent effect of seasonality was also observed. Measurements performed in the spring/summer were, on average, 3 units lower (better) than those obtained in the winter, and these differences paralleled the decrease in the number of exacerbations observed in the spring/summer compared with the winter months. 
Table 3 Baseline characteristics of patients who completed follow up according to the number of COPD exacerbations

\begin{tabular}{|c|c|c|c|}
\hline & $\begin{array}{l}\text { Patients with infrequent } \\
\text { exacerbations* }(n=178)\end{array}$ & $\begin{array}{l}\text { Patients with frequent } \\
\text { exacerbationst }(n=158)\end{array}$ & p value \\
\hline \multicolumn{4}{|l|}{ Baseline characteristics } \\
\hline Sex (no (\%) male) & 174 (97.8\%) & $154(97.5 \%)$ & 0.864 \\
\hline Age (years) & $66.5(7.9)$ & $65.6(8.5)$ & 0.304 \\
\hline BMl $\left(\mathrm{kg} / \mathrm{m}^{2}\right)$ & $27.8(3.9)$ & $27(4.1)$ & 0.076 \\
\hline Years of evolution of COPD & $12.2(9)$ & $13.9(8.4)$ & 0.079 \\
\hline \multicolumn{4}{|l|}{ Severity of COPD, n (\%) } \\
\hline \|I (FEV $\left.{ }_{1} 35 \%-49 \%\right)$ & $90(50.6 \%)$ & $57(36.1 \%)$ & 0.008 \\
\hline III (FEV $1<35 \%)$ & $88(49.4 \%)$ & 101 (63.9\%) & \\
\hline Pack years & $53.1(31.3)$ & $57.1(29.1)$ & 0.222 \\
\hline \multicolumn{4}{|c|}{ Coexisting chronic conditions, n (\%) } \\
\hline 0 & $55(30.9 \%)$ & $47(29.7 \%)$ & 0.396 \\
\hline 1 & $61(34.3 \%)$ & $43(27.2 \%)$ & \\
\hline 2 & $29(16.3 \%)$ & $34(21.5 \%)$ & \\
\hline 3 or more & $33(18.5 \%)$ & $34(21.5 \%)$ & \\
\hline \multicolumn{4}{|l|}{ Hospital admission } \\
\hline No & $141(79.2 \%)$ & $92(58.2 \%)$ & $<0.001$ \\
\hline Yes & $37(20.8 \%)$ & $66(41.8 \%)$ & \\
\hline \multicolumn{4}{|l|}{ Spirometric values } \\
\hline $\mathrm{FVC}, \mathrm{ml}$ & $2254.2(675.7)$ & $2186.8(597.8)$ & 0.336 \\
\hline FVC, \% & 54.5 (13.9) & $52.6(12.8)$ & 0.184 \\
\hline $\mathrm{FEV}_{1}^{\prime}, \mathrm{ml}$ & $1047.9(298)$ & $981.6(271.6)$ & 0.034 \\
\hline$\% \mathrm{FEV}_{1}$ over predicted & $34.2(8.0)$ & $31.8(8.0)$ & 0.006 \\
\hline $\mathrm{FEV}_{1} / \mathrm{FVC}, \%$ & $65.4(13.8)$ & $62.9(13.8)$ & 0.095 \\
\hline \multicolumn{4}{|l|}{ Quality of life scores } \\
\hline SGRQ Symptoms & $44.8(20.1)$ & $52.2(19.6)$ & 0.001 \\
\hline SGRQ Activity & $59.2(22)$ & $66.8(18.9)$ & 0.001 \\
\hline SGRQ Impacts & 35.5 (18.3) & $42.4(16.5)$ & $<0.001$ \\
\hline SGRQ Total & $44.2(17.9)$ & $51.4(15.6)$ & $<0.001$ \\
\hline PCS12 & $39.5(9.7)$ & $36.7(8.3)$ & 0.006 \\
\hline MCS12 & 50.5 (12.2) & $48.6(12.7)$ & 0.168 \\
\hline \multicolumn{4}{|c|}{ Quality of life scores at the end of follow up } \\
\hline SGRQ Symptoms & 34.04 (18.64) & $46.63(18.91)$ & $<0.001$ \\
\hline SGRQ Activity & $59.94(19.98)$ & $67.95(18.57)$ & $<0.001$ \\
\hline SGRQ Impacts & $29.90(18.35)$ & $38.25(18.40)$ & $<0.001$ \\
\hline SGRQ Total & $39.16(16.81)$ & $48.45(16.09)$ & $<0.001$ \\
\hline PCS12 & $40.32(9.26)$ & $36.73(9.12)$ & 0.001 \\
\hline MCS12 & 51.06 (12.11) & $50.16(11.83)$ & 0.502 \\
\hline \multicolumn{4}{|c|}{$\begin{array}{l}\text { Values are mean }(\mathrm{SD}) \text { unless otherwise specified. } \\
\mathrm{BMI}=\text { body mass index; } \mathrm{COPD}=\text { chronic obstructive pulmonary disease; } \mathrm{FVC}=\text { forced vital capacity; } \mathrm{FEV} \mathrm{V}_{1}=\text { forcec } \\
\text { expiratory volume in } 1 \text { second; } S G R Q=S t \text { George's Respiratory Questionnaire; } \mathrm{PCS}=\text { physical summary; } \\
M C S=\text { mental summary. } \\
{ }^{*}<3 \text { in } 2 \text { years. } \\
\dagger \geqslant 3 \text { in } 2 \text { years. }\end{array}$} \\
\hline
\end{tabular}

The data on exacerbations were collected directly by the attending physician and by questionnaires every 6 months. The physicians participating in the study attended about half of the exacerbations, while the others were reported by the patients on follow up visits. This approach has drawbacks because it relies, at least partially, on patient recall. However, some studies have produced reliable data with annual collection of exacerbations, which is more likely to be subject to recall bias than 6 monthly collection. ${ }^{22}$ The observation that hospital admissions had a very similar effect on HRQL to the effect of frequent exacerbations adds validity to our findings, since it is very unlikely that patients will forget an admission to hospital during a 6 month period. Furthermore, on site monitoring of clinical records at the end of the study permitted verification of the number of hospital admissions. Further supporting evidence for the validity of our data is that the mean number of exacerbations reported was 1.5 per year, which is very similar to the number noted in most studies on COPD (range 1-3 exacerbations per year). ${ }^{4}{ }^{8}$ It should also be noted that the unusually high proportion of men enrolled in the study can largely be accounted for by the different smoking patterns among Spanish men and women in the age group of this cohort. ${ }^{23}$ However, because of the small number of women in the group, generalisation of the results to women should be made with caution.
To our knowledge, this is the first study evaluating the long term evolution of HRQL in patients with COPD in a study that is not an integral part of a clinical trial. The patients already had severely impaired HRQL at the time of enrolment into the study (baseline evaluation). All SGRQ scores (except for SGRQ symptoms) were higher (that is, worse) than the scores obtained for the 95th percentile of the general population of similar age; for SGRQ symptoms the score was between the 90 th and 95 th percentiles. ${ }^{24}$ Surprisingly, all SGRQ scores except the SGRQ activity score improved significantly during follow up. The SGRQ total score improved by 4 units (95\% CI -5.44 to -2.65$)$ and the SGRQ symptoms score showed the highest improvement with a mean of 8 units (95\% CI -10.49 to -6.19$)$. This was not a progressive improvement during the 2 year period of the study but occurred predominantly during the first 6 months. This improvement may be interpreted as a study effect, as patients were instructed to contact the attending physician for any exacerbation they experienced and this may have reinforced the feeling of coping with the disease. In addition, pharmacological treatments may have been optimised at entry to the study. In any case, these results highlight the importance of a placebo arm when interpreting the impact of any medical intervention on HRQL. The results of spirometric testing did not reflect the evolution of SGRQ 

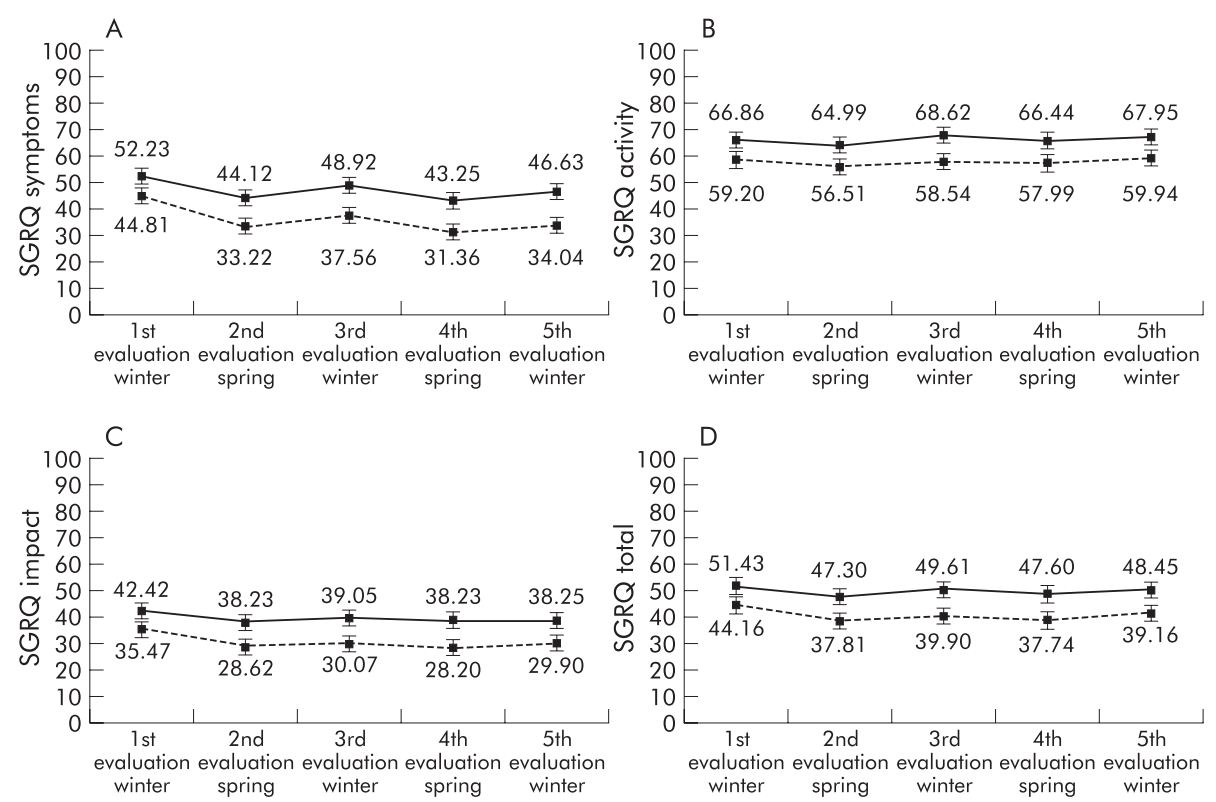

Figure 1 Evolution of (A) symptoms scores, (B) activity scores, (C) impact scores, and (D) total scores of the St George Respiratory Questionnaire (SGRQ) in patients with frequent exacerbations (solid lines) and infrequent exacerbations (broken lines).

scores, highlighting the poor correlation between spirometry and SGRQ, 2526 and the need for a multidimensional evaluation of COPD patients that accounts for other variables in addition to $\mathrm{FEV}_{1} \cdot{ }^{27}$ In contrast to the SGRQ results, the generic questionnaire SF-12 did not detect any significant change during follow up.

Our results contradict those reported in the ISOLDE study, a clinical trial designed to investigate the effects of inhaled fluticasone on the rate of decline in $\mathrm{FEV}_{1}$ and HRQL in patients with COPD. ${ }^{28}$ In the latter study 387 patients were followed for 36 months and HRQL declined progressively in all components of the SGRQ and the SF-36 survey. The SGRQ total score worsened by 2 units per year in the fluticasone arm and by 3.2 units per year in the placebo arm. The differences could be attributed to several factors. Firstly, the population included $38 \%$ smokers compared with only $1.4 \%$ in our study. Although the ISOLDE study observed no differences in HRQL decline rates between smokers and exsmokers, ${ }^{28}$ no other studies have addressed this issue. Secondly, our patients received standard treatment with bronchodilators (including long and short acting $\beta_{2}$ agonists, anticholinergics and theophyllines) often with inhaled steroids, ${ }^{9}$ whereas patients in the ISOLDE trial were only allowed to receive salbutamol, ipratropium bromide, or both, for symptom relief. Some studies have demonstrated the beneficial short term effects of salmeterol ${ }^{18}$ and the effects of the addition of theophylline on improving HRQL in patients with COPD. ${ }^{29}$ The results of our study therefore concur with a 1 year clinical trial by Vincken et al comparing tiotropium and ipratropium. ${ }^{30}$ The patients in this study had similar disease severity (mean $\mathrm{FEV}_{1} 40 \%$ predicted) and were also allowed to use theophyllines, inhaled steroids, and oral steroids. SGRQ total scores improved by a mean of -3.74 units in the tiotropium arm and -0.44 in the ipratropium arm over 1 year. ${ }^{30}$ The observed improvement in HRQL was associated with a reduction in the number of exacerbations from an average of 1.7 per patient in the first year to 1.3 in the second $(p<0.001)$. This may be attributed to a trial effect and has been observed in different studies analysing exacerbations, since the number of exacerbations during the studies is usually lower than the number of exacerbations recorded before the initiation of the trial..$^{28}$ In another observational

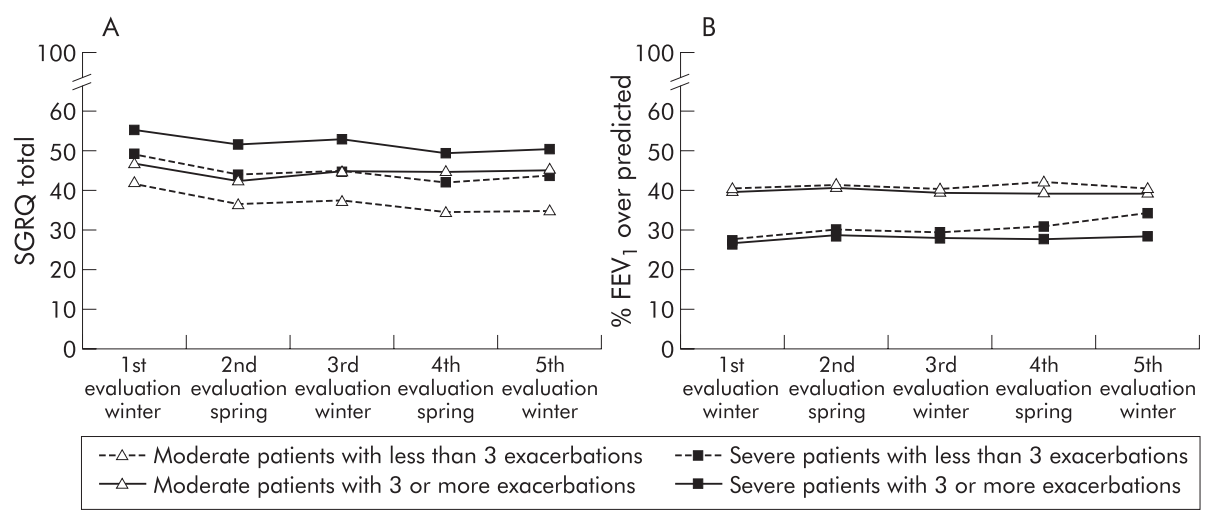

Figure 2 Evolution of the St George Respiratory Questionnaire (SGRQ) total score and FEV 1 percentage over predicted in patients with frequent and infrequent exacerbations according to COPD severity groups. 
Table 4 Generalised estimating equations (GEE) model 1 to evaluate the effect of frequent exacerbations during follow up on five repeated measures of the SGRQ total score* in patients with moderate COPD

\begin{tabular}{|c|c|c|c|c|c|c|}
\hline & $\begin{array}{l}\text { Mean (SE) } \\
\text { coefficient }\end{array}$ & $95 \% \mathrm{Cl}$ & $p$ value & $\begin{array}{l}\text { Mean (SE) } \\
\text { coefficient }\end{array}$ & $95 \% \mathrm{Cl}$ & p value \\
\hline \multirow{2}{*}{\multicolumn{7}{|c|}{ Season }} \\
\hline & & & & & & \\
\hline Winter & - & - & - & & & \\
\hline Summer & $-3.00(0.64)$ & -4.26 to -1.74 & 0.000 & & & \\
\hline \multirow[t]{2}{*}{ Annual rate of change } & & & & $-2.58(0.73)$ & -4.01 to -1.14 & 0.000 \\
\hline & \multicolumn{3}{|c|}{ Differences between patients } & \multicolumn{3}{|c|}{ Differences within patients $\dagger$} \\
\hline \multirow{2}{*}{\multicolumn{7}{|c|}{$\begin{array}{l}\text { Factors } \\
\text { Exacerbations }\end{array}$}} \\
\hline & & & & & & \\
\hline$<3$ & - & - & - & - & - & - \\
\hline$\geqslant 3$ & $5.45(2.20)$ & 1.15 to 9.76 & 0.013 & $1.98(0.97)$ & 0.07 to 3.89 & 0.042 \\
\hline \multicolumn{7}{|l|}{ Hospital admission } \\
\hline No & - & - & - & - & - & - \\
\hline Yes & $1.39(2.40)$ & -3.31 to 6.09 & 0.563 & $1.80(1.06)$ & -0.29 to 3.88 & 0.091 \\
\hline \multicolumn{7}{|l|}{ Dyspnoeaf } \\
\hline 1 & $-7.09(1.74)$ & -10.49 to -3.69 & 0.000 & $0.10(0.77)$ & -1.41 to 1.61 & 0.896 \\
\hline ॥ & $6.36(1.75)$ & 2.92 to 9.80 & 0.000 & $-1.51(0.78)$ & -3.04 to 0.01 & 0.051 \\
\hline III & $17.54(2.52)$ & 12.60 to 22.49 & 0.000 & $-1.83(1.12)$ & -3.02 to 1.36 & 0.457 \\
\hline
\end{tabular}

study, treatment of exacerbations with oral corticosteroids was associated with a prolonged time to the next exacerbation. ${ }^{31}$ In our case, the proportion of exacerbations treated with oral corticosteroids remained unchanged during follow up, thus making any influence of this treatment on the reduction of exacerbations observed during the study very unlikely.

Spencer and Jones ${ }^{32}$ showed that the effect of exacerbations on HRQL may persist for months; however, the greatest improvement in SGRQ scores takes place during the first month after the episode. To avoid interference of the last exacerbation with the SGRQ scores, measurements of HRQL must be done at least 1 month after the last exacerbation and during periods of clinical stability. In fact, the time from the last reported exacerbation to the next HRQL measurement was, on average, 60 days with no significant differences during the study.

Patients with frequent exacerbations have previously been shown to have worse HRQL scores than patients with infrequent exacerbations. Seemungal et $a l^{8}$ evaluated 70 patients and showed that patients who experienced $<3$ exacerbations per year had a mean SGRQ total score 15 points lower than patients with frequent exacerbations at the end of a 1 year follow up (95\% CI -22.3 to -7.8$)$. However, the impact of exacerbations on short term HRQL is similar to the decrease in $\mathrm{FEV}_{1}$ values, and both parameters improved within a few days or weeks. ${ }^{7}$ In a study in patients with chronic bronchitis, the SGRQ total score improved by a mean of 6.92 units in patients in stable phase compared with patients with exacerbations. ${ }^{33}$ From these findings it can be

Table 5 Generalised estimating equations (GEE) model 2 to evaluate the effect of frequent exacerbations during follow up on five repeated measures of the SGRQ total score* in patients with severe COPD

\begin{tabular}{|c|c|c|c|c|c|c|}
\hline & $\begin{array}{l}\text { Mean (SE) } \\
\text { coefficient }\end{array}$ & $95 \% \mathrm{Cl}$ & $\mathrm{p}$ value & $\begin{array}{l}\text { Mean (SE) } \\
\text { coefficient }\end{array}$ & $95 \% \mathrm{Cl}$ & $\mathrm{p}$ value \\
\hline Constant & $41.60(3.40)$ & 34.94 to 48.26 & 0.000 & & & \\
\hline \multicolumn{7}{|l|}{ Season } \\
\hline Winter & - & - & - & & & \\
\hline Summer & $-2.97(0.58)$ & -4.12 to -1.83 & 0.000 & & & \\
\hline \multirow[t]{2}{*}{ Annual rate of change } & & & & $-1.75(1.45)$ & -4.59 to 1.08 & 0.225 \\
\hline & \multicolumn{3}{|c|}{ Differences between patients } & \multicolumn{3}{|c|}{ Differences within patients $\dagger$} \\
\hline \multirow{2}{*}{\multicolumn{7}{|c|}{$\begin{array}{l}\text { Factors } \\
\text { Exacerbations }\end{array}$}} \\
\hline & & & & & & \\
\hline$<3$ & - & - & - & - & - & - \\
\hline$\geqslant 3$ & $2.96(1.96)$ & -1.14 to 6.52 & 0.169 & $-0.42(0.84)$ & -2.06 to 1.22 & 0.618 \\
\hline \multicolumn{7}{|l|}{ Hospital admission } \\
\hline No & - & - & - & - & - & - \\
\hline Yes & $5.53(2.04)$ & 1.52 to 9.53 & 0.007 & $1.61(0.87)$ & -0.10 to 3.32 & 0.066 \\
\hline \multicolumn{7}{|l|}{ Dyspnoea } \\
\hline & $-6.20(3.52)$ & -13.10 to 0.69 & 0.078 & $1.30(1.50)$ & -1.64 to 4.24 & 0.387 \\
\hline ॥ & $5.23(3.40)$ & -1.44 to 11.90 & 0.124 & $-0.42(1.45)$ & -3.27 to 2.42 & 0.770 \\
\hline III & $19.71(3.52)$ & 12.81 to 26.62 & 0.000 & $-2.43(1.51)$ & -5.38 to 0.52 & 0.106 \\
\hline
\end{tabular}


hypothesised that the acute negative effect of exacerbations could accumulate over time and, consequently, patients experiencing a greater number of events can eventually exhibit a marked deterioration in HRQL. However, a deterioration in HRQL could be a risk factor for frequent exacerbations instead of its consequence. This is particularly important since a previous study has shown that a worse HRQL score is a risk factor for readmission due to exacerbations. ${ }^{34}$ In fact, the difference in SGRQ total scores between patients with infrequent and frequent exacerbations in our population $(\mathrm{n}=336)$ was already present at baseline and increased at the end of the 2 year follow up period, especially in patients with moderate COPD $\left(\mathrm{FEV}_{1} 35-50 \%\right)$. Interestingly, the impact of exacerbations on HRQL is modified by COPD severity. Frequent exacerbations were associated with a significantly worse change only among patients with moderate COPD ( 1.98 units by year, $\mathrm{p}=0.04$ ). In patients with severe COPD the difference in the change in SGRQ total score between patients with infrequent and frequent exacerbations was very small and was not significant $(-0.42$ units per year, $p=0.62)$. There are several possible explanations for this unexpected finding: (1) patients with severe disease may interpret any mild increase in symptoms as an exacerbation which means more and probably milder exacerbations; (2) an increase in disease severity implies frequent medical visits and better control of the disease so these patients may benefit more from the study effect; (3) an effect of regression on the mean SGRQ score cannot be ignored but it is difficult to explain why this effect differs according to COPD severity.

In summary, exacerbations have a long term effect on HRQL in patients with moderate COPD. It is therefore crucial to identify efficacious strategies to prevent exacerbations in order to optimise HRQL and reduce costs. ${ }^{35}$

\section{Authors' affiliations}

M Miravitlles, Servei de Pneumologia, Institut Clínic de Pneumologia i Cirurgia Toràcica (IDIBAPS), Hospital Clinic, Barcelona, Spain M Ferrer, À Pont, Health Services Research Unit, Institut Municipal d'Investigació Mèdica, Barcelona, Spain

R Zalacain, Unidad de Patología Respiratoria, Hospital de Cruces, Baracaldo (Vizcaya), Spain

J L Alvarez-Sala, Servicio de Neumología, Hospital Clínico San Carlos, Madrid, Spain

F Masa, Servicio de Neumología, Hospital San Pedro de Alcántara, Cáceres, Spain

H Verea, Servicio de Neumología, Hospital Juan Canalejo, La Coruña, Spain

C Murio, Unitat de Pneumologia, Hospital General de Catalunya, Barcelona, Spain

F Ros, R\&D Department, QF Bayer, Barcelona, Spain

R Vidal, Servei de Pneumologia, Hospital General Vall d'Hebron, Barcelona, Spain

The IMPAC Study was funded by an unrestricted grant from QF Bayer Spain.

\section{APPENDIX: INVESTIGATORS OF THE IMPAC STUDY GROUP}

C Escudero, H. de Asturias (Oviedo); C Sanjuas, H. Del Mar (Barcelona); J Joaquín Cebrián, H. Carlos Haya (Málaga); F Álvarez-Gutiérrez, H Virgen del Rocío (Sevilla); F del Campo, H. Río Ortega (Valladolid); J M Hernández-Valle, H. San Pedro de Alcántara (Cáceres); F Casas, H. Clínico San Cecilio (Granada); S Vilá, C. De la Roza, H. General Vall dHebron (Barcelona); M Blanco, H. Juan Canalejo (La Coruña); G Pérez, H. General de Gran Canaria Dr. Negrín (Las Palmas); J J Blanco, H. Cristal-Piñor (Ourense); A León, H. Puerta del Mar (Cádiz); J Tárrega, H. De Santa Creu i Sant Pau (Barcelona); F J Domínguez del Valle, H. de Navarra (Navarra); L A Ruiz-Iturraga, H. De San Eloy (Vizcaya); J
M Echave-Sustaeta, H. 12 de Octubre (Madrid); J Palop, Rafael Blanquer, H. Dr. Peset (Valencia); O Perelló, Carlos A. Jiménez, H. De la Princesa (Madrid); J Franco, H. Alcira (Valencia); J Garrapiz, L Borderías, H. San Jorge (Huesca); J A Hermida, H. Getafe (Madrid); A Perpiñá, H. Severo Ochoa (Madrid); F Conget, H. Clínico Universitario de Zaragoza (Zaragoza); G Peces-Barba, Fundación Jiménez Díaz (Madrid); N Soler, H. Clínic i Provincial (Barcelona); M C Abellán, H. General Universitario de Murcia (Murcia); M J Mejuto, H. Arquitecto Marcide (La Coruña); M Arévalo, H. General de Albacete (Albacete); C Estirado, H. Txagorritxu (Vitoria); F Renom, H. Joan March (Baleares); M Calle, H. Clínico Universitario San Carlos (Madrid); E Prats, H. Bellvitge (Barcelona); M Iriberri, H. Cruces (Vizcaya); M Vendrell, H. Josep Trueta (Girona); T Lloret, H. General de Valencia (Valencia); M S Prats, H. Germans Trias i Pujol (Barcelona); N Roger, H. Vic (Barcelona); J L Izquierdo, H. Guadalajara (Guadalajara); A Bustamante, H. Sierrallana (Cantabria).

\section{REFERENCES}

1 Sobradillo Pena V, Miravitlles M, Gabriel R, et al. Geographical variations in prevalence and underdiagnosis of COPD. Results of the IBERPOC multicentre epidemiological study. Chest 2000;1 18:981-9.

2 Ferrer M, Alonso J, Morera J, et al. Chronic obstructive pulmonary disease stage and health-related quality of life. Ann Intern Med 1997;127:1072-9.

3 Pawels RA, Buist AS, Calverley PMA, Jenkins CR, Hurd SS on behalf of the GOLD Scientific Committee. Global strategy for the diagnosis, management, and prevention of chronic obstructive pulmonary disease. Am J Respir Crit Care Med 2001;163:1256-76.

4 Miravitlles M, Mayordomo C, Artés M, et al on behalf of the EOLO Group. Treatment of chronic obstructive pulmonary disease and its exacerbations in general practice. Respir Med 1999;93:173-9.

5 Miravitlles M, Guerrero T, Mayordomo C, et al on behalf of the EOLO Study Group. Factors associated with increased risk of exacerbation and hospital admission in a cohort of ambulatory COPD patients: a multiple logistic regression analysis. Respiration 2000;67:495-501.

6 Miravitlles M, Murio C, Guerrero T on behalf of the DAFNE Study Group. Factors associated with relapse after ambulatory treatment of acute exacerbations of chronic bronchitis. A prospective multicenter study in the community. Eur Respir J 2001;17:928-33.

7 Aaron SD, Vandemheen KL, Clinch JJ, et al. Measurement of short-term changes in dyspnea and disease-specific quality of life following an acute COPD exacerbation. Chest 2002;121:688-96.

8 Seemungal TAR, Donaldson GC, Paul EA, et al. Effect of exacerbation on quality of life in patients with chronic obstructive pulmonary disease. Am J Respir Crit Care Med 1998;157:1418-22.

9 Miravitlles M, Alvarez-Sala JL, Lamarca R, et al for the IMPAC Study Group. Treatment and quality of life in patients with chronic obstructive pulmonary disease. Qual Life Res 2002;11:329-38.

10 Alvarez-Sala JL, Cimas E, Masa JF, et al. Recomendaciones para la atención al paciente con enfermedad pulmonar obstructiva crónica. Arch Bronconeumol 2001;37:269-78.

11 American Thoracic Society. Standards for the diagnosis and care of patients with chronic obstructive pulmonary disease. Am J Respir Crit Care Med 1995; 152:S77-120.

12 Jones PW, Quirk FH, Baveystock CM, et al. A self-complete measure of health status for chronic airflow limitation. The St. George's Respiratory Questionnaire. Am Rev Respir Dis 1992;145:1321-7.

13 Ferrer M, Alonso J, Prieto L, et al. Validity and reliability of the St George's Respiratory Questionnaire after adaptation to a different language and culture: the Spanish example. Eur Respir J 1996;9:1160-6.

14 Ware JE, Kosinski M, Keller SD. A 12 -item short-form health survey. Construction of scales and preliminary tests of reliability and validity. Med Care 1996;34:220-33.

15 Alonso J, Prieto L, Antó JM. La versión española del SF-36 Health Survey (cuestionario de salud SF-36): un instrumento para la medida de los resultados clínicos. Med Clin (Barc) 1995; 104:771-6.

16 American Thoracic Society. Lung function testing: selection of reference values and interpretative strategies (statement). Am Rev Respir Dis 1991; 144:1201-18.

17 Jones PW. Interpreting thresholds for a clinically significant change in health status in asthma and COPD. Eur Respir J 2002;19:398-404.

18 Jones PW, Bosh TK in association with an international study group. Quality of life changes in COPD patients treated with salmeterol. Am J Respir Crit Care Med 1997; 155:1283-9.

19 Anthonisen NR, Manfreda J, Warren CPW, et al. Antibiotic therapy in exacerbations of chronic obstructive pulmonary disease. Ann Intern Med 1987; 106:196-204.

20 Miravitlles M, Zalacain R, Murio C, et al on behalf of the IMPAC Study Group. Speed of recovery from acute exacerbations of COPD after treatment with antimicrobials: results of a two-year study. Clin Drug Invest 2003;23:439-50. 
21 Diggle P, Liang K, Zeger SL. Analysis of longitudinal data. New York: Oxford Science Publications, 1994:143-5.

22 Kanner RE, Anthonisen NR, Connett JE for the Lung Health Study Research Group. Lower respiratory illnesses promote $\mathrm{FEV}_{1}$ decline in current smokers but not ex-smokers with mild chronic obstructive pulmonary disease. Am J Respir Crit Care Med 2001;164:358-64.

23 Jiménez-Ruíz CA, Sobradillo V, Gabriel R, et al. Respiratory symptoms and diagnosis of COPD in smokers of various types of tobacco. Results from the IBERPOC Study (in Spanish). Arch Bronconeumol 2002;38:530-5.

24 Ferrer M, Villasante C, Alonso J, et al. Interpretation of quality of life scores from the St. George's respiratory questionnaire. Eur Respir J 2002;19:405-13.

25 Tsukino M, Nishimura K, Ikeda A, et al. Physiologic factors that determine the health-related quality of life in patients with COPD. Chest 1996; 110:896-903

26 De la Iglesia F, De la Fuente $R$, Ramos $V$, et al. Factor analysis of the health related quality of life of patients with stable chronic obstructive pulmonary disease (in Spanish). Arch Bronconeumol 2001;37:410-6.

27 Celli B, Cote CG, Marin JM, et al. The body-mass index, airflow obstruction, dyspnea, and exercise capacity index in chronic obstructive pulmonary disease. N Engl J Med 2004;350:1005-12.

28 Spencer S, Calverley PMA, Burge PS, Jones PW on behalf of the ISOLDE Study Group. Health status deterioration in patients with chronic obstructive pulmonay disease. Am J Respir Crit Care Med 2001;163:122-8.

29 ZuWallack RL, Mahler DA, Reilly D, et al. Salmeterol plus theophylline combination therapy in the treatment of COPD. Chest 2002;119:1661-70.

30 Vincken W, van Noord JA, Greefhorst APM, et al. Improved health outcomes in patients with COPD during 1 year's treatment with tiotropium. Eur Respir J 2002;19:209-16.

31 Seemungal TAR, Donaldson GC, Bhowmik A, et al. Time course and recovery of exacerbations in patients with chronic obstructive pulmonary disease. Am J Respir Crit Care Med 2000;161:1608-13.

32 Spencer S, Jones PW for the GLOBE Study Group. Time course of recovery of health status following an infective exacerbation of chronic bronchitis. Thorax 2003;58:589-93.

33 Doll H, Grey-Amante P, Duprat-Lomon I, et al. Quality of life in acute exacerbation of chronic bronchitis: results from a German population study. Respir Med 2002;96:39-51.

34 Osman LM, Godden DJ, Friend JAR, et al. Quality of life and hospital readmission in patients with chronic obstructive pulmonary disease. Thorax 1997:52:67-71.

35 Miravitlles M, Murio C, Guerrero T, Gisbert R on behalf of the DAFNE Study Group. Pharmacoeconomic evaluation of acute exacerbations of chronic bronchitis and COPD. Chest 2002;121:1449-55.

\section{LUNG ALERT}

A high number of transmissions of H7N7 avian influenza $A$ virus to humans

$\Delta$ Koopmans M, Wilbrink B, Conyn M, et al. Transmission of H7N7 avian influenza A virus to human beings during a large outbreak in commercial poultry farms in the Netherlands. Lancet 2004;363:587-93

$\mathrm{P}$ eople exposed to chickens on Dutch poultry farms affected by H7N7 avian influenza A virus (A/H7) were asked to report signs of conjunctivitis or influenza-like illness from February to June 2003. Of the estimated 3410 or more at risk, 453 had health complaints: 349 conjunctivitis; 90 influenza-like illness, and 67 others. Laboratory confirmation from eye and nose/throat swabs was by RT-PCR or viral culture and typing. A/H7 was detected in $83(23.8 \%)$ patients with conjunctivitis, seven $(7.8 \%)$ with influenzalike illness, and four $(6.0 \%)$ with other symptoms. Influenza-like symptoms were reported less often in those who were A/H7 positive than in those in whom viruses could not be detected. There was one case fatality from respiratory distress syndrome and A/H7 was detected by bronchoalveolar lavage. After 19 people were diagnosed, all workers received influenza virus vaccination and prophylaxis with oseltamivir to reduce the risk of genetic mixing or reassortment of avian and human influenza virus.

This study shows an unexpectedly high number of $\mathrm{A} / \mathrm{H} 7$ transmissions to humans. The virus is highly lethal in chickens but has comparatively low pathogenicity in humans. However, a more virulent virus would have been difficult to contain with current strategies and the study demonstrates the importance of surveillance and planning for possible future outbreaks.

N Navani 